\title{
APÊNDICE PARA OBRA DESCONHECIDA
}

\author{
Luís Filipe Silva ${ }^{1}$
}

(o seguinte conjunto de anotações foi encontrado no disco rígido do único computador sobrevivente à destruição do edifício Coral; o ficheiro estava marcado como backup e referia-se a um outro ficheiro presumivelmente a obra principal -, o qual não se conseguiu encontrar, quer sob o nome referenciado quer sob qualquer outro; o autor deste texto é desconbecido e embora a maioria das referências citadas sejam verídicas, nem a teoria a que se refere o texto nem o presumivel professor que lhe terá dado autoria existem nas bases de dados académicas do mundo inteiro; aferiu-se no entanto que o software em que foi escrito estava registado sob pertença da universidade situada no edifício; pela falta de evidências concretas e a possibilidade forte de se tratar de ficção, conclui-se que deve existir pouca probabilidade de ligação deste documento com o atentado.)

CAP. I - Conspiração sobre a Teoria da Conspiração

$\left.{ }^{1}\right)$ professor emeritus da UPC (Barcelona) onde lecionou sobre os novos modelos políticos de 7PCI a 13PCI; de acordo com o seu blog, desenvolveu aí os fundamentos que dariam origem à teoria dos poderes invisíveis «inspirado pela organização dos diversos departamentos, um padrão de atitudes e procedimentos que surgia da sua interligação eletrónica, e ao qual se obedecia sem grande crítica; era como se fossemos governados por uma vontade maior, invisível mas a que não se podia fugir (...)» (lectures.bhamasi.caltech.edu, 12.05.17PCI)

\footnotetext{
${ }^{1}$ Luís Filipe Silva é autor de O Futuro à Janela (Prémio Caminho de Ficção Científica), Cidade da Carne, Vinganças e (com João Barreiros) Terrarium - Um Romance em Mosaicos além disso tem vários contos, ensaios e artigos em publicações portuguesas, brasileiras e internacionais. Como antologista, organizou Vaporpunk - Relatos Steampunk Publicados sob as Ordens de Suas Majestades (com Gerson LodiRibeiro) e Os Anos de Ouro da Pulp Fiction Portuguesa (com Luís Corte Real).
} 
$\left(^{2}\right)$ uma segunda versão do artigo, um resumo com cariz mais técnico, surgiu na revistapapel Le Nouvel Ordre Mondial com o título «Est-il possible de voir les puissances invisibles?» (Quebéc, 16.03.17PCI)

(3) alcunha espirituosa com que Hamasi costumava referir-se ao colégio de consultores académicos composto por autoridades provenientes de diversas universidades mundiais, cuja função é pronunciar-se anualmente sobre a validade das novas teorias culturais e sociais, e que refletia a sua opinião do mesmo; derivado da lenda de Procrustes.

$\left({ }^{4}\right)$ M. Tensih não seria tão delicado em privado: em discussão com os restantes membros do colégio, afirmava que não tinha «tempo a perder com mais uma teoria da conspiração, inventada por mais um livre-pensante, daqueles que se põem a analisar o tráfego da rede e descobrem fantasmas e esquemas ocultos (...) matemática dúbia e interpretação imberbe» (Mailing-list 3453.google, 31.10.16PCI)

$\left(^{5}\right)$ o corpo estava em elevado estado de decomposição, depois de uma semana na água; o despiste genético não conseguiu provar a 100\% que se tratava de Hamasi (relatório do médico-legista, 20.05.17PCI)

(') nome de solteira da mãe; Hamasi, pela lei de Singapura, não estaria a apresentar um nome falso mas a desenvolver uma segunda identidade (a alteração voluntária de identidade é um direito protegido por vários países da orla do Pacífico desde 5PCI). Contudo, como apenas utilizou essa identidade durante o tratamento psiquiátrico, a imprensa e a comunidade internacional concluiriam apressadamente que Hamasi tinha tentando esconder a verdade sobre a sua condição mental.

(`) segundo o Rig Veda, Varuna guarda as almas de quem morre por afogamento.

$\left(^{8}\right)$ Esta espantosa evidência é difícil de compilar, mas pode ser obtida nas bases de dados dos serviços de necrologia das universidades dos diversos países; alguns, nomeadamente os africanos, irão requerer autenticação por parte da academia que suporta o estudo; outros poderão requerer o uso de meios menos oficiais - aconselha-se o investigador a ter $\mathrm{o}$ 
espírito aberto no que toca a questões éticas, entender os costumes de cada país e concentrar-se nos resultados. Eu própria não teria perseguido esta questão se não tivesse querido falar pessoalmente com alguns dos membros do comité.

(') Dvorak pertenceu ao comité de janeiro a setembro de $16 \mathrm{PCI}$, tendo tido acesso ao corpo da teoria mas nunca chegando a manifestar a sua opinião.

$\left({ }^{10}\right)$ Segundo a caixa preta do avião, esta mensagem teria sido enviada pelo copiloto às 20.35; contudo, este, dos poucos ocupantes a terem sobrevivido, negou a existência de tal mensagem, bem como de que houvesse o problema relatado a bordo. Não foi possível prosseguir a investigação porque o copiloto morreria passadas algumas horas pela administração fatal de insulina, derivada da troca incorreta de etiquetagem dos medicamentos no serviço do hospital (relatório da comissão de investigação do desastre do voo New Pan-American 0743, 30.03.20PCI)

$\left({ }^{11}\right)$ o computador de Tensih foi encontrado nos destroços, mas irrecuperável.

$\left({ }^{12}\right)$ vi-lhe ainda o rosto, pois a entrada da estação onde tínhamos combinado fica a cinquenta metros do cruzamento; o carro dele voou literalmente na minha frente ao ser projetado para fora do viaduto. Não cheguei a prestar atenção ao outro carro.

$\left({ }^{13}\right)$ escrita à mão numa letra muito miudinha; a primeira ex-mulher de Dvorak, que encontrei no velório, ajudou-me a decifrá-la; quando terminou, mudou de atitude e pediume para desaparecer da cerimónia e não voltar a contactá-la.

$\left({ }^{14}\right)$ A lista inclui ainda técnicos de software, analistas demográficos, juristas, cirurgiões, membros de organismos de segurança social, técnicos políticos, legisladores, as respetivas datas e locais de óbito e o tipo de acidente envolvido. 


\section{CAP. II - Uma Nova Camada de Pele}

$\left.{ }^{1}\right)$ inicialmente, apenas a partir dos dez anos, mas a lei tem baixado a idade mínima legal para a adesão à derme, situando-se na maior parte da Europa e Estados Católicos Americanos nos quatro anos, cinco para os Estados Árabes Americanos e Alemanha, e quinze para o Brasil (por ventura do conflito entre as várias culturas de dermes - v. cap. III).

() espátula impregnada de nanócitos-gm com que se raspa as gengivas do recém-nascido

$\left({ }^{3}\right)$ cf. Construindo Cibersacerdotes: A Adesão da Derme como Processo Iniciático na Cultura Protestante, A. Brahm e S. Bram (Londres, 3PCI)

(') Madagáscar é a exceção à regra; a Tanzânia, pelo contrário, sobrevive com uma das dermes mais atrasadas do planeta, depois da catástrofe da erupção do Kilimanjaro provocada pelo projeto África Século XXII.

$\left(^{5}\right)$ nos ECA, por motivos práticos (necessidade de pagar apenas um ato religioso por parte das famílias), o batismo e a ativação da derme começam a juntar-se num só ato, realizado pela figura sacerdotal, que se encontra devidamente certificada pelo Gabinete de Gestão da Plataforma Comum de Comunicação - o que acaba por ter interessantes consequências políticas (cf. ob. cit, A. Brahm e S. Bram, pp. 170-185). Pela natureza da religião, esta tendência é menos forte nos EAA, mas houve estudos que verificaram a intensidade de atuação da derme durante o Salat (cf. «Variação da atividade na nano-derme na rotina diária de dez indivíduos», T. Borme, T. Shackra \& F. Lampreia, Nova Deli, 23PCI).

${ }^{(}{ }^{\circ}$ a tendência tem vindo a propagar-se pelas culturas orientais, onde a dimensão e densidade populacional explica a quantidade de medidas de controlo do nível de saúde geral da população, as quais têm sido alvo de críticas a nível mundial. Segundo Deerk (Antuérpia, 12PCI), «contra a democracia fala a higiene, ou o que passa por higiene, de um povo ou uma cidade ou um estado; defensável? Veja-se o caso de Hong Kong, onde os monitores individuais de saúde estão em constante vigilância pelo Estado e sintomas que 
possam indicar uma das doenças colocadas em lista negra, obrigam o indivíduo a apresentar-se para check-up imediato e iniciar o tratamento, podendo ser preso caso recuse e mantido sob custódia até terminar o processo de cura.» Ou como diz Silverberg (Bagdad, 16PCI), «O corpo deixa de ser pertença do indivíduo e é pertença do Estado - o indivíduo é neste caso ocupante indesejável e por vezes incomodativo (...) a cura, e logo estar vivo, torna-se uma sentença (...)».

(`) designação pela qual a imprensa designou o Primeiro Colapso da Internet durante os primeiros meses após o evento e que seria ocasionalmente utilizada em publicações anteriores ao Segundo.

$\left.{ }^{8}\right)$ a versão 3.3 apenas monitoriza o nível de serotonina, não é capaz de o influenciar.

(9) R. G. Martin ratifica a sua perspetiva contraditória numa entrevista posterior: «a alucinação coletiva a que me referi anteriormente poderá ser explicada, em grande parte, pela adaptação de uma população a uma nova forma tecnológica de comunicação (...) a derme é sem dúvida inofensiva a nível biológico e mental (...) novos estudos convenceramme que prosseguia por uma argumentação errada (...)» (44534US.visual.google, 8.9.3PCI, dois meses depois da tentativa de rapto do filho mais novo)

(10) cf. Efeitos da Exposição Prolongada de Fetos da Cobaia à ação da Nano-Derme, por H. Simmons, Cambridge, 22PCI

$\left({ }^{11}\right)$ comparem a citação mencionada com a seguinte, retirada de um jornal-papel publicado na época: «segundo Herbert Simmons, investigador e obstetra no Bristol General Hospital, "apesar das proteções anunciadas, é expectável que um nível mínimo da nano-derme da mãe ultrapasse a barreira da placenta, transportada no sangue; não me pronuncio sobre o nível de intervenção que terá a nível do feto, uma vez que a programação é extrictamente controlada e poderá não representar qualquer ameaça (...) os testes normais não incidem sobre a presença de nano-derme."” (Bristol Sun, 12.2.23PCI). A citação surge apenas nesta publicação; a entrada do blog foi refeita sete meses mais tarde e não surge sequer no Internet Archive. 
CAP. III - Ordem Mundial, ou Desordem Organizada?

( $)$ utilizamos o conceito tal como descrito por P. Morris (Nova Iorque, 15PCI): «De tal forma complexo e interligado se tornaram os aparelhos que a humanidade inventou para a ajudar a dominar o meio ambiente e proporcionar melhores e crescentes níveis de qualidade de vida, de tal forma dependem as nossas vidas - inclusive literalmente, em certas doenças - da continuação e crescimento deste status quo mecânico e eletrónico, e de tal forma esses mesmos mecanismos se tornaram autónomos, capazes de decidir, escolher e evoluir sem intervenção humana, que a denominação arcaica de "tecnologia" deverá também evoluir para uma "tecno-ecologia", em tudo semelhante, como conceito, à da Natureza. Na verdade, uma Natureza-2, ficando a Natureza-1 como designação base do mundo biológico terrestre como sempre o conhecemos.»

(') a citação não provêm de Kemp, mas é adaptada de uma conclusão do ensaio de Hamasi: «[a disseminação indiscriminada de informação] provoca o surgimento de nódulos autorreguladores que são capazes de produzir informação contraditória que anula o efeito da primeira, e sobre este pano neutral inscrever a sua própria interpretação» e ainda «quem tenha os instrumentos corretos é capaz de determinar o comportamento dos nódulos (...) roubar identidades falsas, obter senhas e contrassenhas e efetuar espionagem de informação de forma barata e imediata».

(3) da mesma forma que a Argélia se tornou nação-escrava em 19PCI perante o consórcio germano-turco com uma divida combinada de 1500 milhões de euros.

$\left.{ }^{4}\right)$ de acordo com a mesma reportagem, são na ordem dos trinta mil, em Zanzibar, concentrados na zona sul da ilha. Os bebés são mergulhados à nascença durante dois dias num líquido inibidor - que é na verdade uma derme de versão mais antiga com a qual a residente encontra incompatibilidades de atualização e logo não se sobrepõe. Embora desta forma estes residentes, que se recusam a aceitar a situação de nação-escrava por questões culturais, consigam fugir ao escrutínio da África do Sul, existe o perigo de submeterem crianças tão novas à atuação de uma derme antiga; o resultado tem-se manifestado na 
decrescente taxa de natalidade, que não pode ser considerada apenas como efeito natural no fluxo da população. Os habitantes aguardam pacientemente «pelo dia em que a dívida esteja paga e possam voltar a ser os donos da terra».

(5) os números do Banco Mundial (relatórios anuais de 20-23PCI) revelam sessenta porcento de insucesso nas iniciativas de adesão de tecnologia moderna por parte dos «Países a Vapon», atribuídas a causas tão diversas como mau planeamento, condições ambientais, instabilidade política, falta de financiamento, falta de competências nos recursos humanos, dificuldades logísticas. Interessante é o facto de nos quarenta porcento restantes, existir consistente e coerentemente controlo e financiamento de países e entidades ocidentais, que reservam para si os direitos subsequentes de exploração e pesquisa durante o primeiro século.

(`) cf. Kropotkin às Avessas, S. Biergenstein e Unidade Pan-Europeia: Tecnocracia com Pernas, M. Holder (ambos Nova Iorque, 19PCI).

CAP. IV - É possível ver os Poderes Invisíveis?

(') compare-se no controlo evidenciado nas estatísticas das aprovações de natalidade na China nos últimos dez anos com o crescimento do volume de abortos espontâneos da PanEuropa e ECA (relatórios do Banco Mundial).

$\left({ }^{2}\right)$ o processo não é perfeito, senão Dvorak teria tido, mais cedo, um possível destino igual aos dos restantes membros do comité, antes que eu própria o conseguisse contactar (obviamente que esta frase não é comprovável cientificamente).

${ }^{(3)}$ embora Hamasi se referisse à citação como estando no blog, não consegui encontrá-la, o que aumenta a necessidade de reproduzir o email na íntegra: «Vou ao limite de crer numa conspiração que me acerca, que tudo conspira contra mim, desde o mais singelo meio de transporte aos mecanismos no meu lar, que vão um a um deixando de me obedecer. A que extremo se torna a perspicácia em paranoia? Recuperar o equilíbrio é essencial, mas como ter a certeza do que sou? Um alvo genuíno? Não um louco convicto? Apenas um acumular 
de evidências que tento negar mas que me procuram, como o facto de tudo se encontrar na normalidade quando estou acompanhado mas começar a funcionar mal quando estou só. Ontem entretive dois professores em casa... a situação estava normal e só não consegui mostrar-lhes os gráficos de evolução das doenças menores porque o ecrã não funcionava (o que é recorrente quando tento apresentar evidências)... quando saíram a luz começou a piscar intermitentemente, o teclado não respondia, a água saía fria e depois suja... não consigo alugar carros, o sistema fica avariado quando entro e volta a funcionar quando saio... como é que posso convencer alguém? É um berdadeio jofo do gato w rato... percberam konteud d maill nao consg escccvr +..."

$\left(^{4}\right)$ os padrões surgem quando menos esperamos: ao comparar as iniciais das primeiras 6 frases do capítulo quarto das versões francesa, inglesa, espanhola e norueguesa do manual de instruções da Plataforma Financeira Comum, utilizado por estes países, chegamos também à designação Varuna. Por sinal, se juntarmos as iniciais dos relatórios do Banco Mundial, dos livros mencionados neste ensaio, e em grande parte dos textos oficiais, encontramos constantemente esta designação. Manipulação? Ou estará esta assinatura digital já impregnada no nosso pensamento, impedindo que [ficheiro corrompido e irrecuperável] 